\title{
Representação espacial de dados eleitorais no Brasil: críticas e possibilidades
}

Artigos Originais

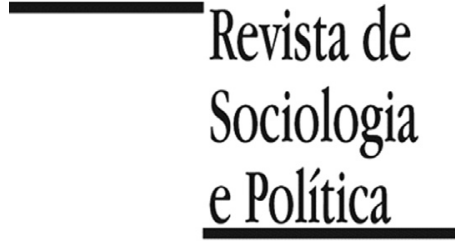

DOI 10.1590/1678-987321297906

\author{
Ivan Jairo Junckes' (iD, Wilson Silva Júnior" (iD, \\ Joseli Maria Silva" (iD), Edson Armando Silva"II iD \\ IPrograma de Pós-Graduação em Desenvolvimento Territorial Sustentável, Universidade Federal do Paraná, Matinhos, PR, \\ Brasil. \\ IIPrograma de Pós-Graduação em Geografia, Universidade Estadual de Ponta Grossa, Ponta Grossa, PR, Brasil. \\ IIIPrograma de Pós-Graduação em História, Universidade Estadual de Ponta Grossa, Ponta Grossa, PR, Brasil.
}

Palavras-chave: ciência política; eleição; representação espacial; mapa; cartograma.

\begin{abstract}
RESUMO Introdução: Os mapas coropléticos proporcionam uma precária representação dos fenômenos de caráter socioeconômico ou político. Ancorados nas poligonais político-administrativas, esses mapas coloridos de estados e municípios destinam-se essencialmente à representação das dimensões territoriais. Áreas com reduzida extensão, mas com alta densidade populacional ou eleitoral, quase desaparecem no mapa. Este artigo discute o uso desses mapas na ciência política e apresenta alternativas que visam a ampliar os recursos de representação espacial dos fenômenos político-eleitorais no Brasil. Materiais e Métodos: Realizamos uma busca dirigida por produções acadêmicas que retratam o problema abordado e realizamos ensaios cartográficos com base em dados do Tribunal Superior Eleitoral relativos ao eleitorado apto para as eleições de 2016. Para as modelagens utilizamos os programas JamoviR para análises estatísticas, Quantum Gis para operações com bases tabulares e expressão temática, Saga Gis 3D e Grass para correção topológica. Resultados: Demonstramos limitações inerentes aos mapas coropléticos e indicamos quatro modelagens cartográficas: áreas iguais, 3D, anamorfose e interpolação. Discussão: As modelagens indicadas constituem alternativas metodológicas e contribuem para ampliar as condições de pesquisa nas áreas de geografia eleitoral e ciência política.
\end{abstract}

Recebido em 9 de Setembro de 2020. Aprovado em 14 de Maio de 2021. Aceito em 25 de Junho de 2021.

\section{Introdução ${ }^{1}$}

$\mathrm{O}$ objetivo deste artigo é discutir as formas de representação espacial dos fenômenos político-eleitorais. Demonstramos algumas discrepâncias inerentes ao uso de mapas coropléticos² na ciência política e apresentamos quatro modelagens alternativas com potencial para ampliar os recursos de mapeamento de dados populacionais referentes às unidades político-administrativas no Brasil.

A interpretação e a análise da espacialização de dados eleitorais, por exemplo, têm sido limitadas por razões intrínsecas à forma dos mapas coropléticos como os conhecemos, mesmo utilizando variação de cores ou formas para tentar contornar as limitações. As dificuldades podem ser bem compreendidas se observarmos na Figura 1 a expressão do eleitorado dos municípios de São Paulo (SP) e Altamira (PA).

No caso do município de São Paulo (SP) precisamos fazer representar os dados referentes a 5.801 eleitores em cada $\mathrm{km}^{2}$, enquanto em Altamira (PA) podemos dispor de mais de $2,2 \mathrm{~km}^{2}$ para alocar a manifestação política de cada eleitor. No mapa resultante desta distribuição, os dados referentes ao primeiro município tornam-se quase imperceptíveis, enquanto aqueles referentes ao segundo ficam superdimensionados, mesmo que sejam utilizadas cores, pontos e figuras para diferenciar a intensidade do fenômeno. Estes são limites intrínsecos da modelagem coroplética que induzem a distorções, falseamentos e equívocos de toda ordem sobre as discussões a respeito dos fenômenos políticos (Field \& Dorling, 2016). 
Figura 1 - Representação do eleitorado no Brasil em mapa coroplético, 2016

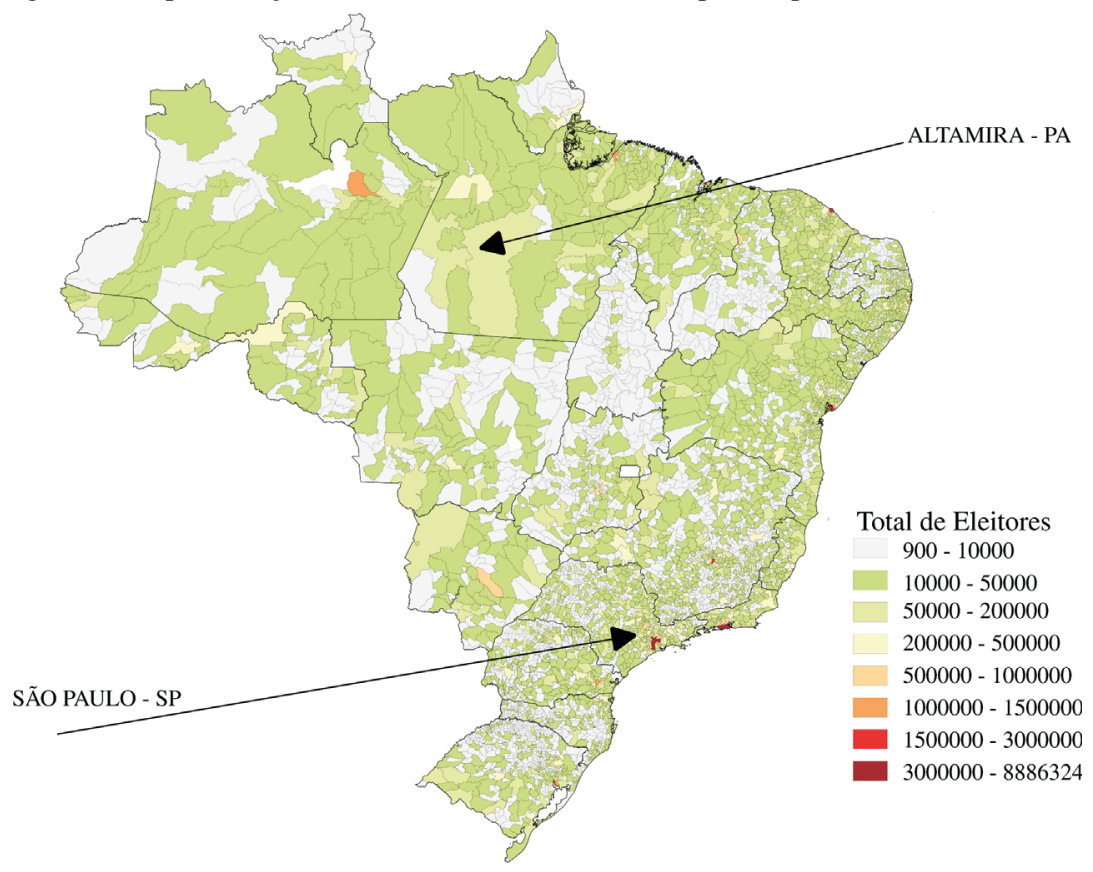

Fonte: Elaborado pelos autores com base nos dados do TSE.

A mesma disparidade ocorre quando tentamos espacializar dados de candidaturas, financiamento, resultados eleitorais ou ainda dados censitários, socioeconômicos ou de avaliação de políticas públicas. Isto ocorre porque menos de $5 \%$ dos municípios no Brasil, comprimidos em menos de 5\% do território nacional, concentram mais do que $50 \%$ dos eleitores brasileiros, ou ainda da população. A relação é inversamente proporcional se considerarmos os municípios com maiores áreas, 5\% deles estão espalhados por 50\% do território e abrigam apenas 6,5\% dos eleitores e aproximadamente o mesmo percentual da população brasileira.

A correlação entre as variáveis 'número de eleitores' e 'quilômetros quadrados' nos municípios brasileiros é 0,29 , quando calculada ( $\log 10)$ pelo coeficiente ' $r$ ' de Pearson com $p$-valor menor que 0,01. Ou seja, a correlação entre estas variáveis amplamente utilizadas para representação espacial de fenômenos político-eleitorais em pesquisas nas áreas de ciência política ou geografia eleitoral é fraca. A mesma carência de correlação tende a se repetir entre as poligonais político-administrativas, determinadas que são em quilômetros quadrados, e os índices e indicadores de caráter socioeconômico que utilizamos para a análise de políticas públicas no Brasil, tais como IDH, IFDM, mortalidade infantil, escolaridade, expectativa de vida, PIB ou VAB per capita, Gini, dentre outros.

Para a engenharia cartográfica e para a geografia faz todo sentido a preservação prioritária dos critérios político-administrativos e dos elementos cartográficos de escala (fenômeno), projeção (ponto de vista) e exatidão (precisão e acurácia) que conferem identidade a essas áreas do conhecimento. Todavia, para a ciência política contemporânea parece não haver muitas razões para que a representação temática do poder político continue sendo baseada em quilômetros quadrados em plena economia terciária superior.

O mapa é em si um recurso político porque ao mesmo tempo em que ele expressa significados, também se torna um elemento de constituição das próprias relações políticas. A maioria dos leitores de nossos trabalhos deposita 
considerável confiança na representação e busca nos mapas uma objetividade e acurácia que eles não possuem por si só. Não percebem, e muitas vezes nós, pesquisadores, tampouco, que o processo de mapeamento é essencialmente político e o que é visto como política é também construído pelo mapeamento (Black, 2000).

A ciência política pode "ganhar" ao adotar perspectivas metodológicas e teóricas interdisciplinares, pode obter muito mais da cartografia do que uma figura ilustrativa de localização e intensidade do fenômeno que ela investiga, pode aprimorar a representação simbólica do poder espacializado. A isto nos dedicamos neste artigo. Com base na bibliografia crítica à tradição cartográfica de mapas coropléticos indicamos neste texto quatro modelagens com potencial para aprimoramento da representação espacial do fenômeno político populacional.

Para alcançar o objetivo proposto foi realizada uma busca dirigida por trabalhos acadêmicos e artigos publicados em periódicos científicos das áreas de geografia e ciência política que exemplificam a representação cartográfica como ferramenta de análise político-eleitoral no Brasil. Posteriormente realizamos ensaios indicativos capazes de gerar maior expressividade para as dinâmicas político-eleitorais ou socioeconômicas dos municípios brasileiros.

São diversas as ferramentas construídas para representação espacial nestes últimos anos. Cada uma delas oferece vantagens e desvantagens, e deve ser avaliada em função do que seus desenvolvedores se colocam como problemas a serem resolvidos. Entre as ferramentas com possibilidades de um bom uso no campo da representação cartográfica de fenômenos sociais apresentamos algumas no campo do software livre na Tabela 1.

A escolha das ferramentas informáticas para realizar este experimento foi orientada (1) pela capacidade de produzir diferentes representações cartográficas coerentes com as diversas perguntas de pesquisa; (2) por serem acessíveis gratuitamente e preferencialmente distribuídas na forma de software livre; (3) por contar com uma comunidade robusta de desenvolvimento de maneira a garantir no futuro a continuidade da incorporação de novas tecnologias; e (3) por apresentar usabilidade facilitada que permita a incorporação por profissionais da área de humanas. Nossa escolha recaiu, então, nos softwares livres Quantum Gis para operações com bases tabulares e expressão temática, Saga Gis para operações de modelagem 3D e GRASS para correção topológica. Para a construção da base temática deste artigo utilizamos os dados do eleitorado apto para o pleito de 2016, disponibilizados pelo repositório de dados eleitorais do Tribunal Superior Eleitoral (TSE, 2021). Os dados utilizados estão disponíveis em .csv para consulta e download no repositório Kaggle (2020). Os projetos montados para os ensaios estão disponíveis para visualização e manipulação no sítio GIS-Browser-memoriasdigitais.uepg (2021).

O artigo está estruturado em duas outras seções além desta introdução e das conclusões. Na segunda seção apresentamos a crítica ao modelo de representação cartográfica coroplética, especialmente em seus limites para a análise das dinâmicas político-eleitorais. Na terceira parte apresentamos as modelagens e ensaios de representação em áreas iguais, 3D, anamorfose e interpolação como recursos que ampliam nossas capacidades para as análises na ciência política, e na quarta seção apresentamos as nossas conclusões.

\section{A crítica ao modelo coroplético de representação cartográfica do fenômeno político-eleitoral}

Nesta seção argumentamos que a modelagem de mapas coropléticos baseados nas poligonais cartográficas fixadas pela divisão político-administrativa supre com limitações a necessidade de representação e análise dos fenômenos 


\begin{tabular}{|c|c|c|c|c|c|}
\hline Ferramenta & Acessibilidade & $\begin{array}{l}\text { Tecnologia e comunidade de } \\
\text { desenvolvimento }\end{array}$ & Usabilidade & Amplitude de recursos & Pontos fortes \\
\hline Philcarto & $\begin{array}{l}\text { Gratuito, mas sem } \\
\text { disponibilizar o } \\
\text { código fonte }\end{array}$ & $\begin{array}{l}\text { Limitado. Software maduro, mas não } \\
\text { faz geoprocessamento, é um software } \\
\text { de cartomática (atua apenas na } \\
\text { representação) com a aplicação de dia- } \\
\text { grama triangular, análise de superfície } \\
\text { de tendência e outras possibilidades }\end{array}$ & $\begin{array}{l}\text { Pequena curva de } \\
\text { aprendizado }\end{array}$ & $\begin{array}{l}\text { Limita-se à representação espacial de } \\
\text { dados estatísticos }\end{array}$ & $\begin{array}{l}\text { Ampla gama de recursos em cartografia } \\
\text { temática; Permite a construção de } \\
\text { gráficos através de cálculos estatísticos } \\
\text { complexos e automatizados }\end{array}$ \\
\hline Khartis & Software Livre & Desenvolvimento promissor & Fácil e Intuitivo & $\begin{array}{l}\text { Limita-se à representação espacial de } \\
\text { dados estatísticos }\end{array}$ & $\begin{array}{l}\text { Cartografia Temática com relativa am- } \\
\text { plitude de recursos }\end{array}$ \\
\hline Quantum Gis & Software Livre & $\begin{array}{l}\text { Amplíssima comunidade de } \\
\text { desenvolvimento com plugins para os } \\
\text { mais diversos problemas }\end{array}$ & Curva média de aprendizado & $\begin{array}{l}\text { Com plugins e integração, cobre quase } \\
\text { todas as áreas do geoprocessamen- } \\
\text { to, integração com softwares Grass, Sa- } \\
\text { ga e R possibilita automação na cons- } \\
\text { trução de bibliotecas de mapas }\end{array}$ & $\begin{array}{l}\text { Construção da Base Cartográfica; } \\
\text { Cálculos espaciais; representação } \\
\text { cartográfica e é possível operar em } \\
\text { diversas áreas desde a medicina até } \\
\text { geologia, passando pelas engenha- } \\
\text { rias, história, antropologia etc. }\end{array}$ \\
\hline GRASS & Software Livre & $\begin{array}{l}\text { Software Maduro com comunidade } \\
\text { ativa }\end{array}$ & Curva alta de aprendizado & $\begin{array}{l}\text { Cobre todas as áreas do } \\
\text { geoprocessamento }\end{array}$ & $\begin{array}{l}\text { Análise topológica. É o único software } \\
\text { completamente topológico que permite } \\
\text { a generalização de conjuntos de } \\
\text { polígonos mantendo a topologia dos } \\
\text { vértices unidas. }\end{array}$ \\
\hline SAGA GIS & Software Livre & Software maduro e comunidade ativa & Curva média de aprendizado & $\begin{array}{l}\text { Análise de imagens, construção de } \\
\text { Base, geoestatística }\end{array}$ & $\begin{array}{l}\text { Análise, classificação, generalização e } \\
\text { conversão de imagens e vetores }\end{array}$ \\
\hline GEODA & Software Livre & $\begin{array}{l}\text { Software em desenvolvimento com } \\
\text { comunidade ativa }\end{array}$ & $\begin{array}{l}\text { Pequena Curva de } \\
\text { Aprendizado }\end{array}$ & $\begin{array}{l}\text { Cobre as funcionalidades da } \\
\text { geoestatística básica }\end{array}$ & Geoestatística \\
\hline
\end{tabular}

Fonte: Elaborado pelos autores. 
eleitorais, pois a dinâmica política exige ênfase nos fluxos das relações de poder que se modificam constantemente no tempo e no espaço, trazendo desafios de aprimoramento para a representação cartográfica. Não se trata, entretanto, de qualquer desqualificação dos mapas coropléticos em si, eles são plenamente úteis para representação de informações onde a extensão é uma dimensão importante do fenômeno, como a expansão da cultura da soja ou um zoneamento espacial.

Bertin, no final da década de 1960, já chamava a atenção para a escolha da melhor variável visual para uma boa representação do fenômeno (Bertin, 1986). Nos estudos político-eleitorais, sociodemográficos, econômicos, de violência e criminalidade, de saúde pública e outros que se proponham tomar como unidades de análise os municípios brasileiros, sempre haverá problemas e limitações que exigem um desenho metodológico com estatísticas, indicadores de concentração espacial ou outra forma de apresentar as análises de forma coerente e fidedigna.

Havemos de considerar, tal qual indica Monmonier (2018), as questões envolvendo agregação, homogeneidade em unidades de área, métodos de classificação, mapeamento de proporções e taxas para dar suporte teórico aos tipos de mapas analisados. Se faz necessário procurar equilibrar as vantagens e desvantagens da seleção das unidades espaciais de análise, abrangência geográfica do estudo, disponibilidade de dados socioeconômicos para essas unidades, tipo de análise e as técnicas de representação cartográfica para a exposição da análise. Não podemos, portanto, indicar uma solução "correta e completa". Nosso limite é explorar as possibilidades de ferramentas mais adequadas para responder nossas perguntas de pesquisa.

O mapa não é o espaço em si, mas uma forma de comunicação da interpretação do fenômeno espacial. Devemos considerar que ele está imbuído da intencionalidade de quem promove a ação comunicativa, o mapeamento. Cartografar ou mapear possui um sentido duplo. Em primeiro lugar, o mapa nunca será a realidade em si, mas uma expressão criada de uma dada interpretação espacial de um fenômeno. Em segundo lugar, uma vez criado, o mapa constitui uma parte da realidade espacial, já que é por meio dele que as possibilidades de leitura de um determinado fenômeno são possíveis.

As bases cartográficas foram construídas para o domínio do espaço, inicialmente gravadas em pedras, argilas, peles de animais, papiros e outros meios que foram paulatinamente sendo aprimorados, passando dos mapas elaborados em papéis e coloridos manualmente aos mapas digitais. $\mathrm{O}$ surgimento de modelos computacionais no início da década de 60 (sistemas CAD) impulsionou novos métodos e procedimentos que foram sendo aprimorados, tal qual os SIGs (Sistemas de Informações Geográficas) que surgiram nos anos 1990 e ampliaram enormemente a capacidade temática das representações cartográficas.

Historicamente, à cartografia coube o registro dos elementos espaciais (localizar, nomear, medir e representar) e, por isso, esta área do conhecimento se constituiu em um recurso e uma forma de exercício de poder. O processo de cartografar cria uma representação seletiva dos espaços que é reproduzida socialmente no processo de comunicação e o resultado é sempre uma escolha que implica priorizar alguns elementos em detrimento de outros. A cartografia não é, portanto, uma técnica objetiva e neutra, mas uma prática política, impregnada de intencionalidade daquilo que se quer expressar.

Os mapas são dotados de simbolismo e ideologia, com potencial de fazer aparecer ou silenciar relações de poder. Todavia, seu poder é relativizado pelo seu caráter tecnocrático, de conhecimento impessoal que imprime a noção de uma ação esvaziada de seu conteúdo social e político (Harley, 2009). Os 
processos cartográficos são atos intencionais que exigem dos agentes de pesquisa uma vigilância e reflexibilidade sobre valores e crenças que farão parte do processo de cartografar. Observando o dimensionamento da representação eleitoral exibidos na Figura 1 deveríamos questionar os motivos pelos quais nos conformamos em fazer quase desaparecer a expressividade dos maiores colégios eleitorais do país. Poderíamos fazer o mesmo questionamento se estivéssemos tratando de espacializar dados, índices, taxas ou indicadores socioeconômicos reveladores de dinâmicas políticas ou de avaliação de políticas públicas, por exemplo.

O mapeamento do poder político no eixo euro-estadunidense, e mais especificamente da política eleitoral, tem sido objeto de trabalho da geografia eleitoral pelo menos desde o Séc. XIX, sustentando-se fundamentalmente em três domínios: padrões de voto, influências geográficas nas eleições e a geografia da representação eleitoral. Parte dessa história pode ser observada em https://www.loc.gov/item/a40001834/, especialmente no conjunto de mapas elaborados entre 1883 e 1889 para representar espacialmente os resultados das eleições estaduais e presidenciais estadunidenses entre os anos de 1824 e 1888 (Hewes \& Gannett, 1883).

A elaboração de mapas ocorrida há mais de um século demorava meses e a sua difusão alcançou algumas poucas centenas de pessoas durante a década seguinte da sua publicação. Em contraste, uma busca no Google pelo termo "red blue maps", em 2015, retornou mais de um bilhão de resultados com mapas coropléticos de eleições ocorridas nos Estados Unidos, ou mesmo das eleições de 2014 no Brasil, quando se confrontaram Aécio Neves e Dilma Rousseff no segundo turno.

Dos bilhões de mapas depositados nas redes sociais, poucos deles, bem poucos talvez, foram produzidos na academia, seja na geografia eleitoral ou na ciência política. Impulsionadas pela expansão das máquinas e pela incorporação de conhecimentos em softwares, as modelagens computacionais que espacializam o voto se tornaram populares e as práticas acadêmicas são forçadas a compartilhar sua identidade com a percepção e (re)elaboração cartográfica realizada pelo público. Crampton $(2009$, p.843) retrata uma invasão da geografia pela arte e pela política, movidas que têm sido pelos sistemas de informações geográficas (SIGs). Aos poucos, a geografia eleitoral torna-se performativa, participativa e militante a ponto de o autor falar em Participatory GIS (PGIS) e afirmar que "Mapas e participação política são bons parceiros".

Todavia, a inter-relação entre geografia e política tem sido acompanhada com dificuldades pela academia. Mesmo que reconheçamos que as relações de poder se realizam espacialmente e que, portanto, o estudo do poder (na ciência política) não poderia se realizar sem alguma correspondência com o estudo do espaço (na geografia), Herb et al. (2009) afirmam que a representação espacial de fenômenos eleitorais tem sido negligenciada na ciência política estadunidense. Os autores apontam como hipótese para essa situação o fato de que em nenhuma das áreas de estudos predominantes da ciência política nos EUA (escolha racional, estudos comportamentais e desenvolvimento político) os estudantes têm o mapeamento espacial do poder como ferramenta metodológica. Propositivamente, Mellow afirma que "O mapeamento é uma maneira de a ciência política se livrar de parte de sua insularidade e tornar sua experiência mais relevante e acessível ao grande público a que serve" (tradução livre desde Herb et al., 2009, p. 339).

Analisando o mesmo fenômeno, Jones \& Clark (2020) afirmam que nas áreas de formação em ciência política o espaço é concebido como um meio vazio, uniforme e sem características, que ganha sentido somente quando animado pelo poder do Estado na ação política. As análises das condições 
${ }^{3}$ Sobre as transformações nas geografias eleitorais no Brasil, ver Terron (2012); Rodrigues-Silveira (2013); Samagaio (2014). histórico-geográficas e dos padrões espaciais, objeto de exame próprio da geografia eleitoral, são excluídas das análises políticas: “...existe uma tendência entre geógrafos e cientistas políticos de ignorar ou preferir não reconhecer as contribuições acadêmicas do outro por causa da ótica da própria disciplina" (tradução livre desde Jones \& Clark, 2020, p. 472).

Poderíamos argumentar que as conclusões de Herb (2009) e Jones \& Clark (2020) se limitam ao ambiente acadêmico estadunidense. Todavia, e embora tenhamos vários autores que trabalham a temática no Brasil citados neste artigo, Nicolau \& Oliveira (2017) realizaram mapeamento da produção acadêmica da ciência política no país e nenhuma referência interdisciplinar referente à temática "espaço" ou "geografia política" é relatada no estudo que cobre o período 1966-2015. Em outro trabalho com o mesmo alcance temporal sobre a ciência política no Brasil, de Avritzer (2016), a geografia recebe raras referências ao longo dos seus treze capítulos. Em um deles, a geografia eleitoral alcança algum protagonismo quando Trindade (2016) relata a experiência em pesquisas eleitorais por parte da ciência política na Universidade Federal do Rio Grande do Sul (UFRGS) no período entre 1968 e 1980, com destaque para o Núcleo de Pesquisas e Documentação da Política Rio-Grandense (NUPERGS) e seu banco de dados da política estadual.

Um quadro menos insular é encontrado por Gonçalves (2016) em sua pesquisa sobre a relação entre a geografia eleitoral e a ciência política brasilei$\mathrm{ra}^{3}$. Em 35 trabalhos analisados o autor identifica dois blocos de pesquisa: um caracterizado pela relação entre sistema eleitoral e o eleitorado, com foco nos padrões territoriais, e o outro caracterizado pela associação entre resultado eleitoral e (perfil do) território e eleitorado. No primeiro grupo, a utilização da cartografia eleitoral é exceção em razão da própria metodologia. No segundo, os textos mais recentes fazem uso de mapas temáticos (coropléticos ou de símbolos proporcionais), aos quais o autor dirige a seguinte conclusão crítica: “...apenas unidades administrativas foram usadas para medir os fenômenos sociais. As unidades administrativas quase nunca correspondem à territorialidade social" (Gonçalves, 2016, p. 67).

As constatações de Gonçalves (2016) são bastante distintas daquelas que podemos observar em publicações euro-estadunidenses sobre a espacialização da territorialidade social, dentre as quais Black (2000); Herb et al. (2009); Field \& Dorling (2016); Kerski (2016); Gusein-Zade \& Tikunov (2017); Harris et al. (2017); Johnston, Pattie \& Manley (2017); Nusrat (2017); Ourednik (2017) e Forest (2018). O reconhecimento preliminar da preocupação com a correspondência entre a área territorial e a natureza populacional dos dados da territorialidade social é comum nesses autores, possivelmente porque no sistema de representação majoritária as duas variáveis são necessariamente interdependentes. No sistema proporcional tal correlação parece não constituir uma preocupação, talvez porque a área do distrito não implica perda ou ganho de posição eleitoral de cadeiras.

Com o objetivo de exemplificar a frágil correspondência entre área e territorialidade social nos trabalhos acadêmicos no Brasil, encontramos 21 publicações em uma busca dirigida no Google Acadêmico por teses, dissertações e artigos publicados em periódicos nas áreas de ciência política e geografia eleitoral que utilizam recursos cartográficos para representar espacialmente o fenômeno político-eleitoral. Destas, dezesseis se limitam a mapas coropléticos: Jacob et al. (2009); Terron (2009); Amorim Neto, Cortez \& Pessoa (2011); Barros (2013); Marzagão (2013); Rodrigues-Silveira (2013); Samagaio (2014); Carvalho (2015); Corrêa (2015); Magalhães, Silva \& Dias (2015); Meireles \& Rubim Andrade (2017); Faganello \& Fernandes (2018); Power \& Rodrigues-Silveira (2019); Braga \& Zolnerkevic (2020); Hernández 
\& León (2020); Nafalski (2020). Quatro trabalhos agregam círculos proporcionais às cores: Jacob et al. (2011); Nicolau \& Terron (2012); Pereira (2014); Augusto (2017). Apenas um dos artigos, Barros \& Nagy (2016), apresenta cartogramas que utilizam círculos proporcionais e anamorfose para representar, respectivamente, quantidade e percentual da votação de um candidato ao senado nas eleições de 2014.

O resultado dessa busca indica que embora tenhamos produzido amplo arsenal de tecnologias computacionais de representação espacial nas últimas décadas, o dinâmico fenômeno eleitoral continua sendo representado por mapas coropléticos que obedecem à rigidez da divisão político-administrativa oficial constituída por município, microrregião, mesorregião e Unidades da Federação.

É certo que "o espaço do político necessita de recortes territoriais institucionalizados, fechados e estáveis, para implementação das alianças e ações da campanha eleitoral", tal qual afirma Terron (2009, p. 55). Todavia, as ciências geográfica e política possivelmente perdem potência interpretativa e analítica ao se conformar aos limites dessa institucionalização territorial na representação espacial dos fenômenos políticos.

Field \& Dorling (2016) foram precisos ao apontar que embora os mapas coropléticos distorçam bastante a maneira como vemos os resultados das eleições, eles (os mapas) não são de todo culpados pelos paradoxos que portam. Alguns problemas já são desafios bastante complexos para serem representados em tabelas estatísticas e gráficos, tal qual as escolhas políticas referentes às áreas com densidade populacional muito variada. O mapeamento coroplético herda essa limitação e a ela adiciona a mimese.

Embora o aprimoramento nos SIGs tenha proporcionado que a relação de cores, anteriormente binárias ou "chapadas", pudessem assumir um extenso gradiente representativo da proporcionalidade da votação, ainda é impossível dimensionar, tal qual sugere Black (2000), quantas vezes o número nove pode ser mais colorido que o número um. Ou ainda, determinar quantas vezes a escura tonalidade relativa à (sobre)densidade gerada pela compressão dos 8.886 .324 eleitores nos $1.532 \mathrm{~km}^{2}$ do município de São Paulo (SP) consegue ser mais expressiva que a mais clara tonalidade relativa à (sub)densidade dos 7.687 votantes distribuídos nos $80.006 \mathrm{~km}^{2}$ do município de Atalaia do Norte (AM).

Esforços para contornar as limitações de representação intrínsecas à modelagem coroplética incluem a adoção de pontos e símbolos para dimensionar os valores a serem representados. No primeiro caso, plota-se um determinado número proporcional de pontos, e, no segundo, círculos ou outras formas geométricas assumem tamanhos proporcionais aos valores. Ambos os recursos resultam em avanços no sentido de ampliar as possibilidades para representar espacialmente os fenômenos político-eleitorais, tal qual pode ser observado na Figura 2 e na Figura 3. Para efeitos comparativos reproduzimos em menor escala o mapa coroplético apresentado na Figura 1.

Cores são mais adequadas para representação de áreas, a nuvem de pontos é mais adequada para representação de densidade e círculos proporcionais expressam melhor quantidades. A combinação desses recursos pode ser utilizada para expressar mais de uma variável no mesmo cartograma, como o tamanho do colégio eleitoral e a proporção de votos em determinado partido ou candidato. Todavia, essas técnicas limitam-se à projeção dos dados no mapa. A metodologia cartográfica e as técnicas computacionais desenvolvidas nas últimas décadas nos permitem ir além e adotarmos modelagens geoestatísticas para projetar representações espaciais abrindo outras perspectivas de análise.

Com base em Black (2000); Gonçalves (2016); Field \& Dorling (2016); Nusrat \& Kobourov (2016); Ondrejka (2016); Nusrat (2017); Ourednik (2017); 
Figura 2 - Representação do eleitorado no Brasil em mapa de pontos (.DOT)

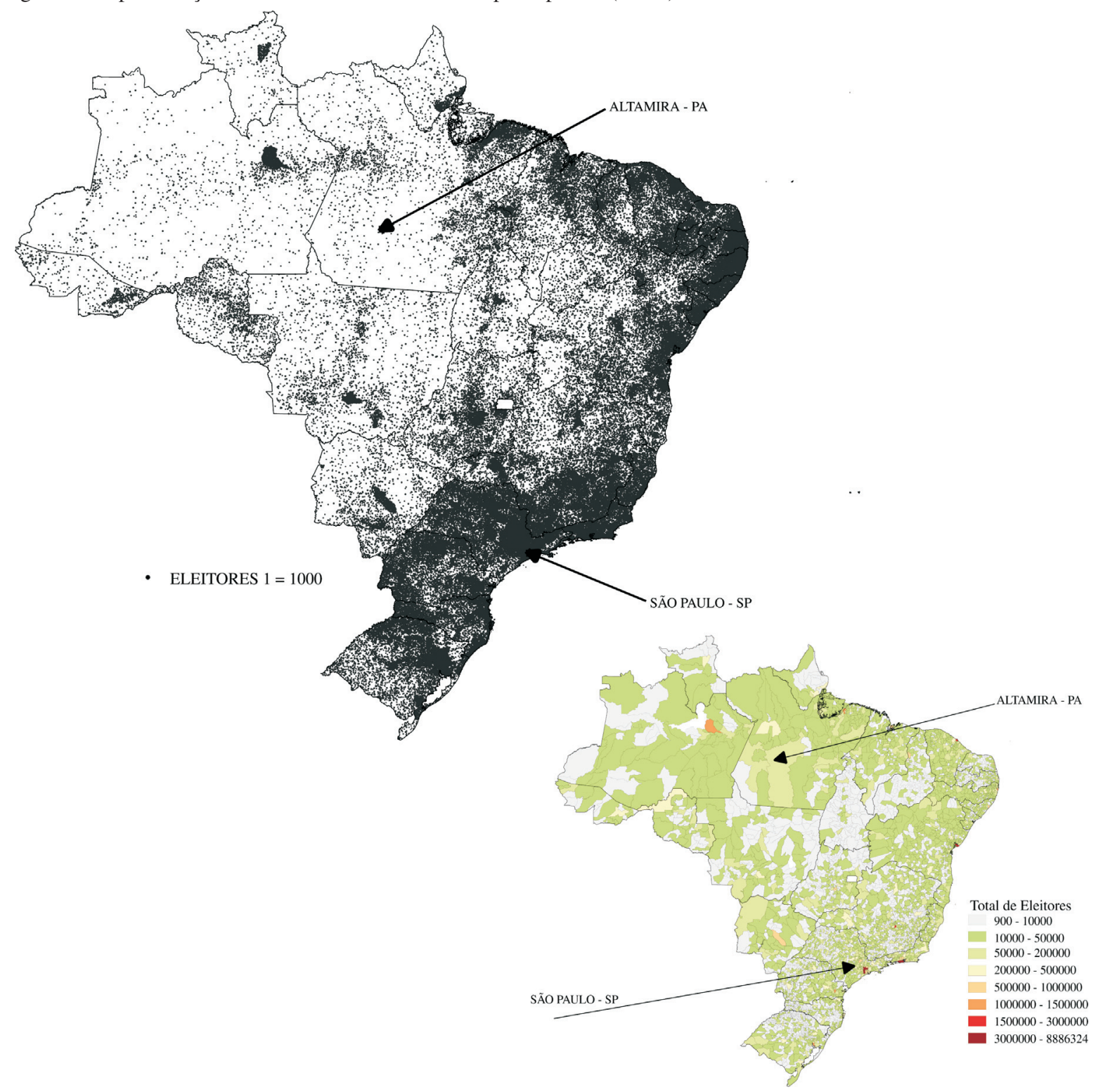

Fonte: Elaborado pelos autores com base nos dados do TSE.

Dutenkefer (2018); Johnston et al. (2018); Li \& Aryana (2018); Barreto, Kosminsky \& Esperança (2018), dentre outros trabalhos, apresentamos a seguir quatro modelagens que apresentam inovações quando comparadas com os mapas coropléticos, de pontos ou círculos proporcionais.

\section{Modelagens para uma representação espacial do Brasil eleitoral}

Nesta seção discutimos quatro possibilidades capazes de minimizar parcialmente as limitações identificadas nos mapas coropléticos discutidos anteriormente. A utilização de diferentes recursos de representação implica um tensionamento em torno de uma tradição visual já internalizada que, embora seja limitada, está sedimentada na constituição de nossas imaginações espaciais. As quatro modelagens analisadas apresentam qualidades no sentido da redução das distorções coropléticas e da ampliação dos recursos de representação da territo- 
Figura 3 - Representação do eleitorado no Brasil em mapa de círculos proporcionais

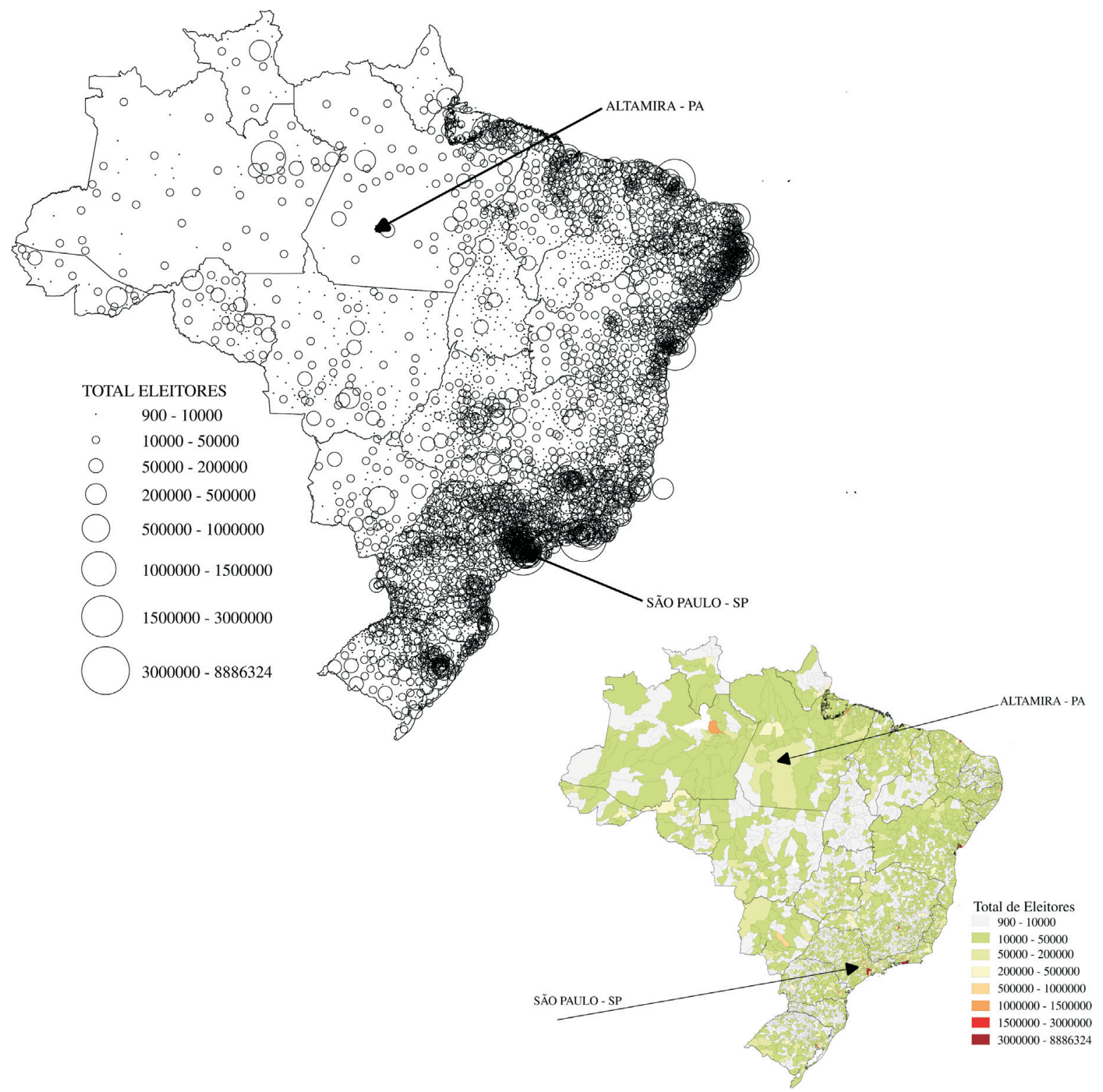

Fonte: Elaborado pelos autores com base nos dados do TSE.

rialidade social, embora cada uma delas apresente também limites e potencialidades.

\section{III.1. Áreas iguais}

A modelagem de cartograma por áreas iguais é uma esquematização da imagem gráfica ou mapa que busca minimizar determinadas diferenças e amplificar as semelhanças de acordo com o objetivo da representação. Para tanto, é gerado uma grade regular de figuras geométricas (triângulos, quadrados, pentágono, hexágonos ou octógonos) onde a cada elemento equivalente é atribuído um determinado valor, que pode ser acompanhado de textura e coloração, distribuído no espaço esquemático.

Em função da condição de relativa equivalência entre as áreas de suas unidades político-administrativas e das discussões a respeito das assimetrias de representação política no parlamento, a Grã-Bretanha tem sido um dos laborató- 
rios de aprimoramento dessa modelagem ao desenvolver formas de representar votações ocorridas entre os bretões há mais de um século. A Figura 4 mostra dois cartogramas de áreas iguais representativos dos resultados das eleições gerais de 1895 na Grã-Bretanha e do referendo sobre a permanência do Reino Unido na União Europeia em 2016.

Esta modelagem tem sido pouco utilizada no Brasil, todavia, um ensaio detalhado sobre os passos para elaboração de um cartograma de áreas iguais foi elaborado por Barreto, Kosminsky \& Esperança (2018), estando disponível na página eletrônica do Laboratório da Visualidade e Visualização da Escola de Belas Artes da Universidade Federal do Rio de Janeiro (LabVis - EBA), link https://labvis.eba.ufrj.br/projetos/um-novo-mapa-para-o-brasil/. Na proposta, cada Unidade da Federação assume uma figura geométrica hexagonal, triangular, retangular ou circular que pode ser colorida ou texturizada na proporção da intensidade do fenômeno a ser representado, tal qual pode ser observado na Figura 5.

O cartograma de áreas iguais reduz consideravelmente as distorções de área quando as variáveis área e eleitores são inversamente associadas. Considerando as Unidades Federativas (UF), no caso do Estado do Amazonas, por ex., uma vasta área pouco povoada teria sua dimensão reduzida enquanto o Estado do Rio de Janeiro teria sua área expandida. Em ambas as situações ocorre um relativo alívio nas distorções comumente observadas nos mapas coropléticos com base político-administrativa. Todavia, no caso dos estados de Sergipe ou Alagoas, ambos com pouca área e eleitores, estes seriam equivalentemente representados aos estados de Minas Gerais ou Bahia.

Aplicado aos municípios brasileiros o cartograma de áreas iguais apresentaria vantagens consideráveis em função da assimetria entre as áreas dos municípios. Considerando que $25 \%$ dos maiores municípios no país concentram aproximadamente $82 \%$ do território, em áreas iguais esses municípios passariam a deter, obviamente, $25 \%$ do "território remodelado". Gerar um cartograma de áreas iguais para os 5.570 municípios não coube no escopo deste artigo em função da complexidade de cálculos de proximidade e vizinhança

Figura 4 - Cartogramas de área igual em 1895 e 2016
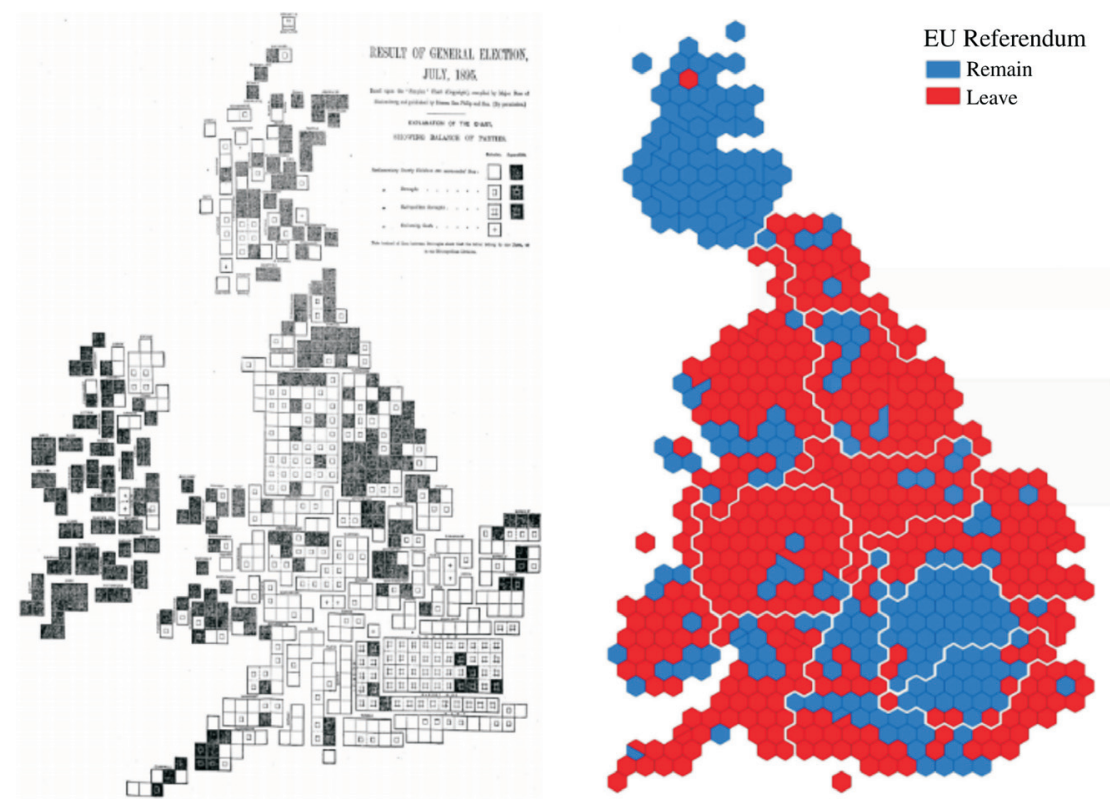

Fonte: Field \& Dorling (2016, p. 205); Johnston et al. (2018, p. 04), respectivamente. 
Figura 5 - Representação esquemática por UF dos resultados do Exame Nacional Ensino Médio, Brasil, 2014

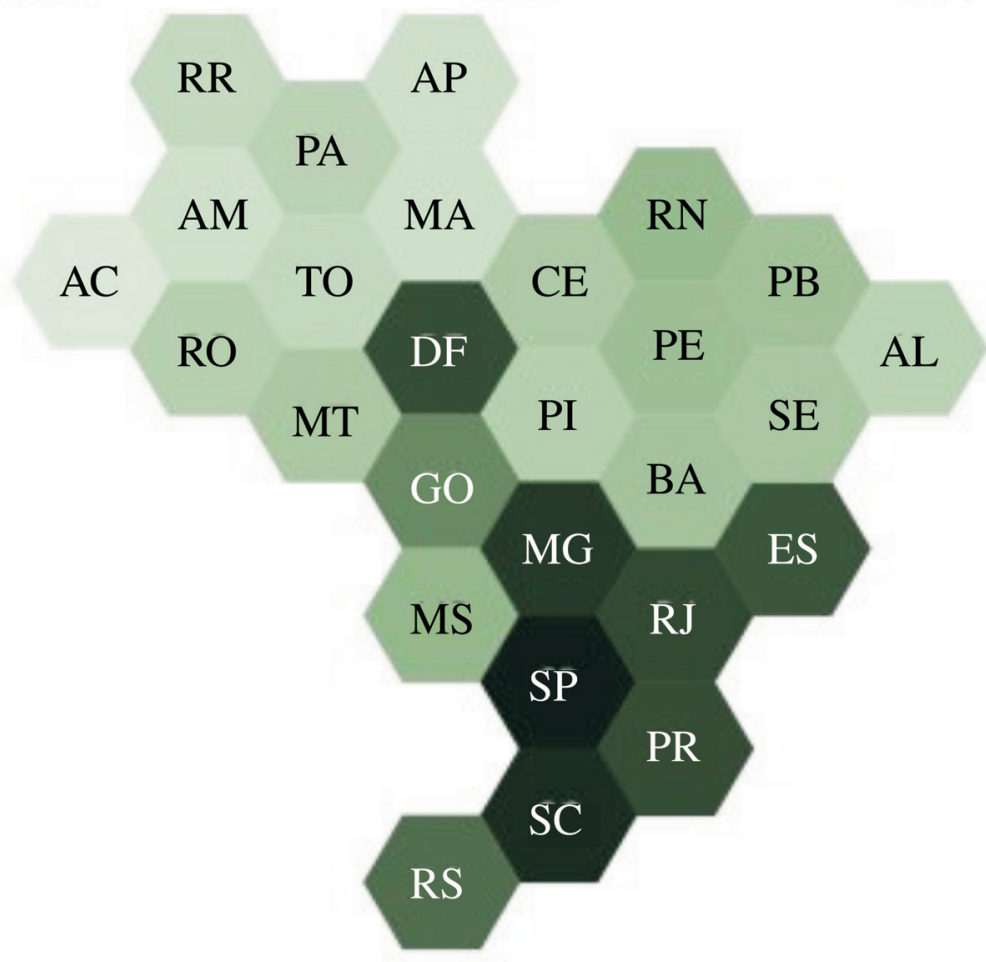

\section{Natural Sciences}

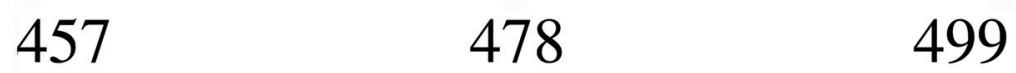

Fonte: Barreto, Kosminsky \& Esperança (2018, p. 60).

necessários para a produção do mapa, restando como tarefa para próximos trabalhos.

Tal qual todas as modelagens, a adoção da técnica de áreas iguais depende de um cálculo custo/benefício que envolve desde a curva de aprendizado pelo pesquisador até a capacidade mediana de interpretação pelo usuário ou leitor, podendo-se mesmo discutir a sua compatibilidade para a aplicação em nível municipal. De toda forma, podemos preliminarmente reconhecer sua contribuição para reduzir a desproporção do dado populacional x território quando comparada com o mapa coroplético tradicional, embora ela ainda mantenha distorções de representação do fenômeno quando as áreas são pequenas e pouco povoadas, pois estariam superdimensionadas, como é o caso de metade dos municípios brasileiros que apresentam área menor que $1.000 \mathrm{~km}^{2}$ e menos de 10.000 eleitores. As modelagens 3D e anamorfose, que apresentamos a seguir, buscam reduzir tais distorções.

III.2. Representação $3 D$

Na representação tridimensional, aos valores X e Y, que constituem o plano bidimensional norte/sul e leste/oeste em um mapa, é inserido o valor Z, que constitui um terceiro eixo para comportar, em projeção, a intensidade do fenômeno que se busca representar. A geração de um cartograma 3D parte de 
um conjunto amostral de pontos que são interpolados, gerando um conjunto de pixels com o valor da amostra de cada ponto calculado segundo um algoritmo. Ele pode ser formado de grades regulares, aproximando-se as superfícies através de um poliedro com dimensões variadas cujo ponto amostral está em seu centro, ou de grades triangulares, que constituem uma malha ligando o ponto inicial diretamente aos pontos mais próximos. Existem centenas de algoritmos interpoladores, os mais comuns são Inverso da Distância, Vizinho Mais Próximo, Krigagem e TIN (Câmara, Davis \& Monteiro, 2001).

Com auxílio de programas de computação e monitores adequados, os cartogramas 3D podem ser colocados em perspectiva $360^{\circ}$ para exploração e geração de inúmeras imagens. Em função da didática que a modelagem 3D proporciona para os estudantes, cuja habilidade com novas tecnologias amplia a sua capacidade de interpretação, Kerski (2016) afirma ser essa a modelagem mais indicada para estimular o pensamento espacial e crítico na academia. A utilização recorrente desta modelagem habilita o estudante, assim como pesquisadores, para a exploração do fenômeno em seus mais diversos ângulos, literalmente.

Diversas experiências com a modelagem 3D instruem a sua aplicabilidade para a representação de dados político-eleitorais, dentre elas Field \& Dorling (2016) sugerem que a proporcionalidade de uma votação seja representada em camadas coloridas nas mesmas áreas, possibilitando, assim, a fusão de vários mapas em apenas um. Ourednik (2017) propõe a elevação de terreno em 3D de formas a preservar a intuitiva configuração usual da distribuição político-administrativa e incorporar a distorção/ajustamento para representação do fenômeno sobre a área.

A partir da indicação de Ourednik (2017), realizamos um ensaio para a representação do número de eleitores nos municípios brasileiros, apresentado na Figura 6. Para efeitos comparativos, novamente reproduzimos em menor escala o mapa coroplético já apresentado na Figura 1. Ambas as representações expressam os mesmos dados com as cores variando do verde (menor número de eleitores) para o vermelho.

Para a simulação exibida na Figura 6 utilizamos uma grade regular com o algoritmo vizinho natural que consiste na interpolação pela média ponderada do valor de cada amostra, em relação ao valor da amostra vizinha, construindo um conjunto de pixels com valores de aproximação relativos à distância entre os pontos amostrais conferidos pelo método de voronoy para maior precisão. Como referência adotamos o centroide dos perímetros municipais e aplicamos um sombreamento em transparência de $70 \%$, evidenciando a rugosidade na modelagem dos dados. Partindo do centroide geramos uma grid (imagem) com pixel de 1.000 metros quadrados, derivando para o conjunto de pixels vizinhos até localizar outro centroide, atribuindo ao conjunto de pixels entre os centroides um valor de proporção entre as duas amostras.

Entre os limites desta modelagem estão uma possível confusão com a topologia do território, o sombreamento de dados quando observados obliquamente, limitação para representação de áreas de concentração de percentagens de votos por municípios e a quase dependência de recursos avançados de processamento e visualização para a sua exploração. Todavia, alcançadas essas condições, tornam-se infinitas as perspectivas proporcionadas pelo dinamismo das imagens para a exploração e análise de resultados de pesquisas nos campos da política e socioeconomia. Este cartograma poderia também representar qualquer parcela dos eleitores, dados de candidaturas, de financiamento eleitoral ou resultados eleitorais, inclusive de plebiscitos e consultas públicas ou ainda índices socioeconômicos aplicáveis às áreas da ciência política ou sociologia. 
Figura 6 - Representação do eleitorado no Brasil em cartograma 3D
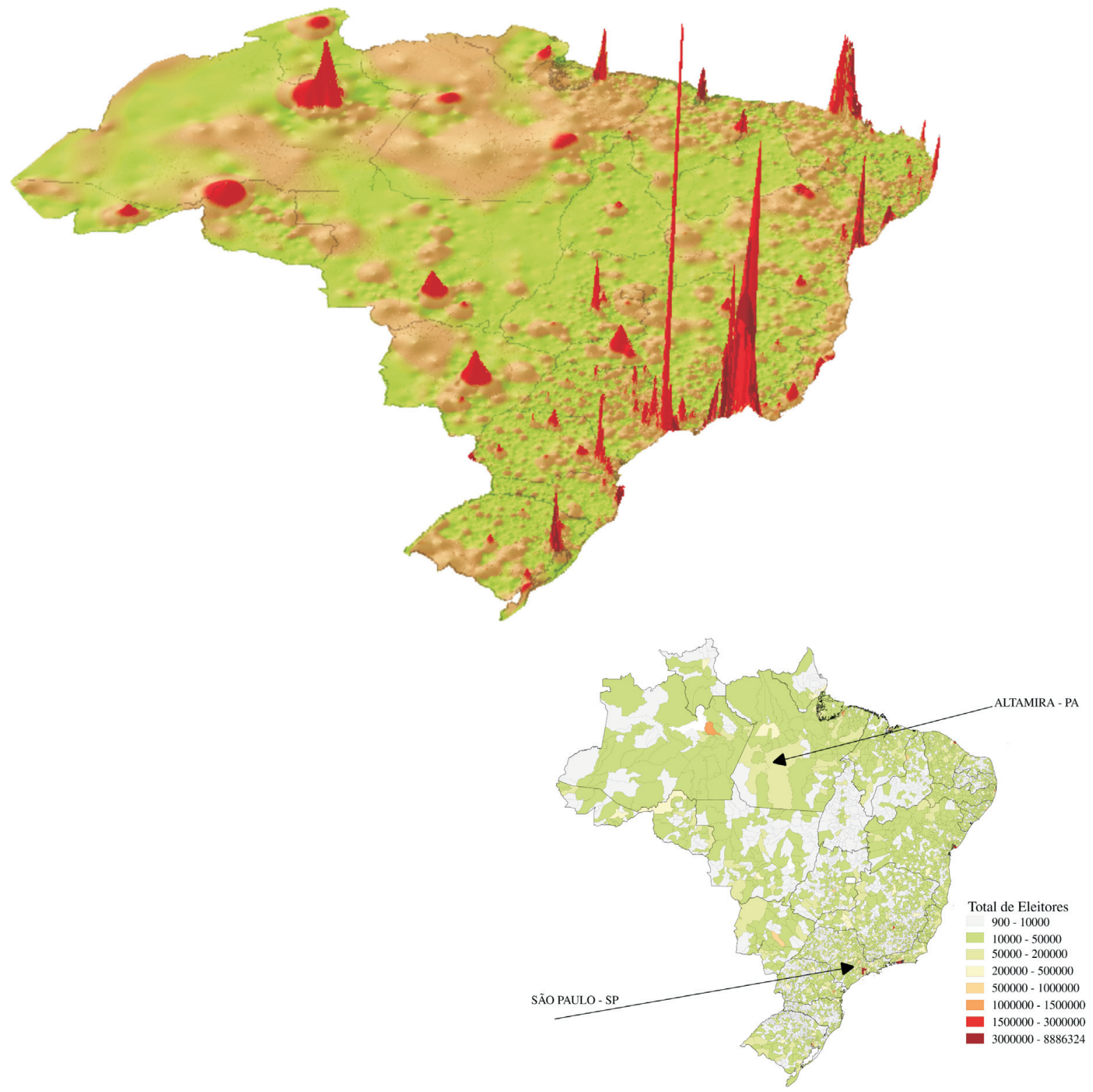

Fonte: Elaborado pelos autores com base nos dados do TSE.

Em função dos rápidos avanços tecnológicos e da popularização de ferramentas computacionais, possivelmente em curto espaço de tempo a representação 3D alcançará protagonismo nos mais variados campos do mundo da virtualização. Nos espaços acadêmicos é importante estimular a atualização e o aprendizado de representações dinâmicas a fim de acompanhar os avanços nos processos de comunicação social e a fim de aprimorar nossas referências de interpretação e análise dos fenômenos políticos, tal qual já alertado por Herb et al. (2009).

\section{III.3. Anamorfose}

A modelagem anamórfica consiste na transformação da área da poligonal político-administrativa expressa em quilômetros quadrados, ajustando-a à temática a ser representada. Desta forma, a área do território assume uma 
dimensão proporcional aos valores de dados político-eleitorais ou mesmo socioeconômicos.

Para a sua representação, parte-se da cartografia administrativa, aplicando-se um cálculo de correlação entre a área e o novo valor a ela conferido. Neste caso, o mapa passa a ser uma imagem que coloca em primeiro plano a variável política ou populacional, alterando as dimensões do mapa original, onde o que prevalece são os quilômetros quadrados da área física político-administrativa. Esta abordagem utiliza um modelo de forças exercidas a partir de cada centroide do polígono, atuando na reposição das coordenadas dos perímetros na proporção inversa à distância, cabendo ao operador atribuir o número de interações desejadas, mantendo as relações de vizinhança.

Nas últimas décadas, muitas inovações foram implementadas nos algoritmos visando a otimizar a precisão estatística e geográfica e a preservar os contornos das formas adjacentes. Em função das inovações, diversos autores apontam para a anamorfose como sendo um aprimoramento dos recursos de representação espacial de dados multidimensionais, dentre eles, Herb et al. (2009); Dutenkefer (2010, 2018); Field \& Dorling (2016); Gonçalves (2016); Nusrat \& Kobourov (2016); Ondrejka (2016); Forest (2017); Gusein-Zade \& Tikunov (2017); Li \& Aryana (2017); Markowska (2019).

Todavia, é preciso reconhecer que a anamorfose em si não pode ser considerada uma inovação, pois, muito antes dos sofisticados algoritmos de cálculos utilizados para a distorção e ajustes de áreas, cartogramas anamórficos físicos com dados comparativos das magnitudes da área e população de diferentes países ilustraram atlas escolares estadunidenses entre 1837 e 1897 (Nusrat \& Kobourov, 2016).

Gonçalves (2016) e Dutenkefer (2018) discutem avanços da análise espacial com aplicações estatísticas em SIGs e destacam a capacidade que a anamorfose tem de promover o deslocamento da ênfase do espaço físico para o fenômeno a ser representado. Avaliação semelhante pode ser verificada em Herb et al. (2009) e em Forest (2018). Ambos destacam a capacidade da anamorfose para a correção de vieses provocados pela insuficiência das tonalidades utilizadas em outras modelagens e para que a ciência política demonstre cartograficamente tanto os resultados de suas pesquisas como suas análises.

Vários exemplos de anamorfose como resultado de mudanças e aprimoramentos na cartografia britânica são descritos por Field \& Dorling (2016). A recuperação da história do mapeamento do voto no Reino Unido revela a constituição de um relativo consenso em torno de um formato comum, todavia múltiplo para distintos propósitos, centrado nos cartogramas de área igual e anamórficos.

Em outra aplicação da modelagem, Li \& Aryana (2017) propõem uma variação anamórfica com base esférica a partir de um grid de intensidade básico. Além de exemplos de representação da distribuição global da população humana, do PIB e da emissão de CO2, os autores apresentam os resultados da aplicação de sua proposta para a representação dos votos do colégio eleitoral na eleição presidencial de 2016 nos EUA.

Com base nessas experiências, elaboramos um cartograma anamórfico com o quantitativo de eleitores nos municípios brasileiros, apresentado na Figura 7. Mantendo um padrão para os ensaios, reproduzimos em menor escala o mapa coroplético de referência. Ambas as representações expressam os mesmos dados e possuem o mesmo intervalo de classes (cores) variando do verde para o vermelho, passando pelo amarelo. 
Figura 7 - Representação do eleitorado no Brasil em cartograma anamórfico

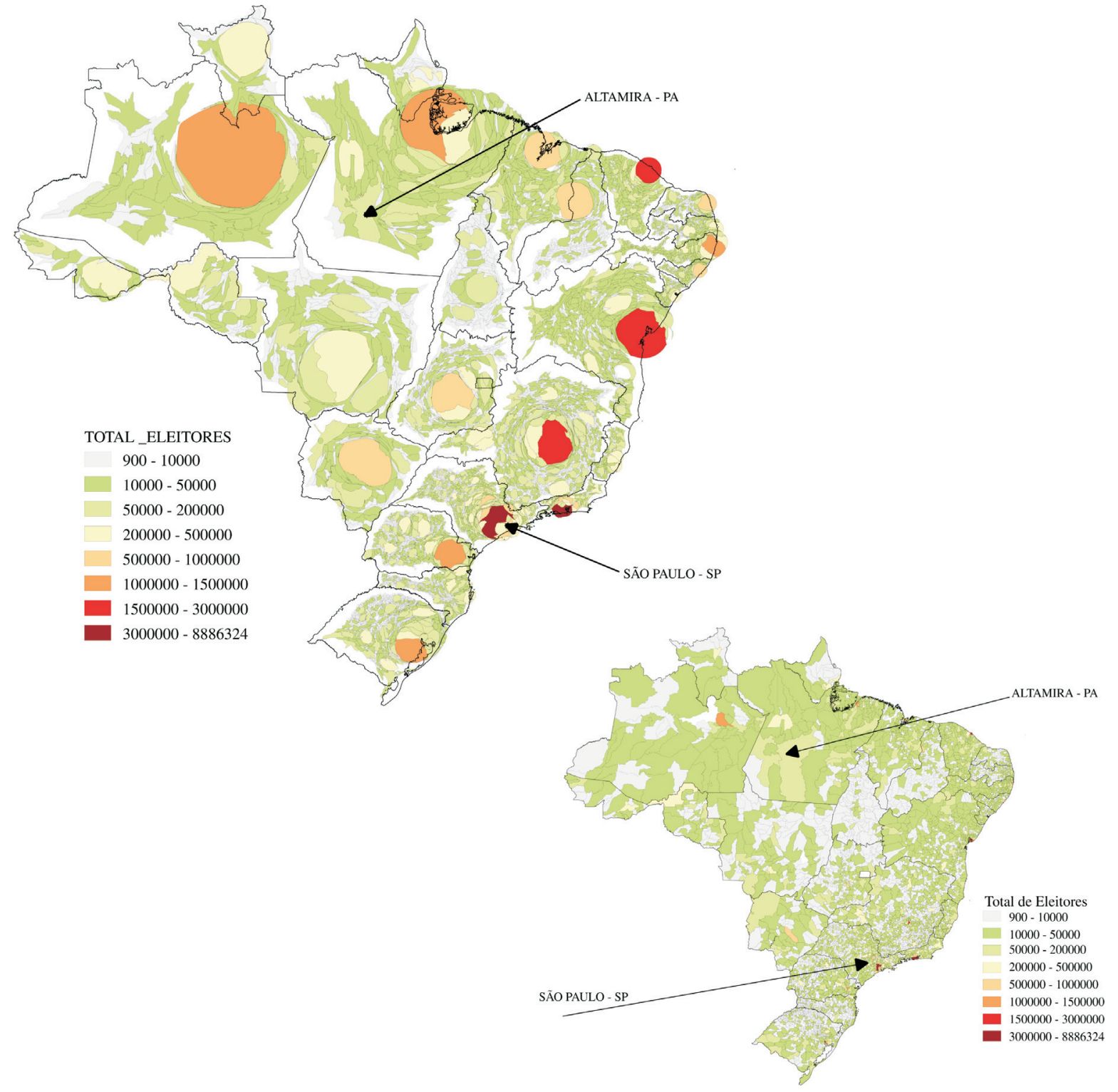

Fonte: Elaborado pelos autores com base nos dados do TSE.

Para esta elaboração utilizamos o software Qgis 3, tendo sido aplicado o plugin Cartogram3 com cinco interações, que calcula a distorção a partir do centroide do polígono. Realizamos inicialmente um ensaio anamórfico abrangendo todos os municípios nos limites do território nacional. Obtivemos um cartograma excessivamente distorcido, apresentando considerável dificuldade de reconhecimento e interpretação dos resultados. Optamos, então, por uma solução intermediária: geramos um cartograma anamórfico para cada Estado e os "encaixamos" nos seus respectivos limites político-administrativos. Perdemos a relação de cada município com a totalidade do país, mas preservamos a sua relação com a UF, constituindo um ganho relativo pois a maior referência de projeção política de um município é efetivamente seu próprio Estado e não necessariamente o país como um todo. Ademais, a imagem resultante coadunase com a organização regional da Justiça Eleitoral no Brasil. Tal qual observamos na modelagem 3D (Figura 6), no cartograma anamórfico (Figura 7) poderiam estar representados dados de candidaturas, de financiamento eleitoral, 
resultados eleitorais ou mesmo índices socioeconômicos ou de avaliação de políticas públicas.

A interpretação do mapa produzido pela anamorfose é relativamente dependente do conhecimento prévio dos polos de concentração populacional, ou eleitoral como utilizado no ensaio, e sua localização geográfica aproximada. Todavia, ao alcançar essa condição, o analista perceberá no mapa expressões do fenômeno em estudo bem pouco perceptíveis no mapa coroplético. Em Minas Gerais, por exemplo, o eleitorado da região metropolitana de Belo Horizonte é quase imperceptível no mapa coroplético, enquanto aparece na modelagem anamórfica como um expressivo núcleo eleitoral. No Paraná, de forma semelhante, evidencia-se Curitiba e os núcleos regionais de Ponta Grossa, Londrina, Maringá e Cascavel. No sítio eletrônico GIS-Browser, acessível a partir do link http://memoriasdigitais.uepg.br/maps/CARTOGRAFIA_ELEITORAL, é possível visualizar e manipular a representação anamórfica do eleitorado em cada UF em separado.

A deformação anamórfica é fruto de um sofisticado ajuste e correção das discrepâncias entre a área e o dimensionamento do fenômeno por vizinhança, seja ele eleitoral ou de avaliação de políticas públicas. A exigência de recursos computacionais e a dissonância cognitiva provocada no leitor do cartograma podem constituir uma limitação para a adoção e difusão desse recurso. Entretanto, o deslocamento da zona de conforto estabelecida pela modelagem coroplética seguramente contribui para o aprimoramento de nossa capacidade de elaboração, leitura e interpretação de dados político-eleitorais.

\section{III.4. Interpolação}

Classicamente, a análise espacial se caracteriza pela identificação de padrões espaciais relacionados entre si. Para tal, utiliza-se pontos, linhas ou polígonos (áreas) para representar os lugares (objetos). A modelagem por interpolação rompe com essas referências e gera "manchas de calor", ou de densidade por vizinhança, para operar a representação espacial do fenômeno. O processo de interpolação tem por finalidade gerar uma extrapolação continuada do fenômeno observado, utilizando cálculos de análise espacial para gerar uma área de abrangência no entorno do ponto amostral ou de amortecimento (Hengl, 2009; Bosque-González et al., 2015).

A correlação espacial é apenas um método de produção de uma imagem através de pontos amostrais do fenômeno, a formação cluster envolve a classificação de uma imagem contínua (gerada por uma interpolação), transformando-a em uma imagem discreta, construindo um conjunto de classes de agrupamentos de pixel de acordo com o valor, também chamado de classificação não supervisionada.

Embora a modelagem por interpolação seja bastante frequente em estudos na geografia física (especialmente geologia e climatologia), e em algumas áreas da saúde e administração de negócios, dificilmente localizamos trabalhos acadêmicos de investigação política que tenham utilizado a ferramenta no Brasil. Em um texto hispânico, Bosque-González et al. (2015) relatam experiências que utilizam a modelagem para fins de investigação em ciências humanas e sociais na Espanha.

Nas buscas realizadas por experiências de referência, encontramos um serviço comercial de análise de resultados eleitorais. A plataforma oferece identificação e análise de dados por candidato e por local de votação, apresentando os resultados de densidade na forma de "mapas de calor". A partir da interpolação de dados de eleições anteriores, o serviço realiza projeção de tendências de expansão de desempenho eleitoral local por candidato e partidos. 
Verificada a carência de material acadêmico, mas dadas as potencialidades da modelagem, realizamos um exercício de interpolação com o quantitativo de eleitores nos municípios brasileiros apresentado na Figura 8. Seguindo o padrão utilizado nos ensaios anteriores, reproduzimos em menor escala o mapa coroplético (Figura 1) para fins comparativos.

A Figura 8 foi obtida calculando-se o desvio padrão entre os pontos amostrais (centroides) a partir das técnicas de interpolação. Após esse primeiro passo, calcula-se um cluster de $\mathrm{n}$ classes reclassificando a grid e aproximando os valores das diferenças em uma determinada classe e, em seguida, filtra-se o resultado para se remover os pixels espúrios através de um filtro de maioria. Após a remoção da "sujeira" o resultado é vetorizado e suavizado em seus contornos, expressando o fenômeno.

Embora os dados representados em ambas as imagens da Figura 8 sejam os mesmos, o resultado para fins de interpretação e análise do fenômeno eleitoral é bastante diverso, pois no cartograma interpolado podemos identificar "dois

Figura 8 - Representação do eleitorado no Brasil em cartograma de interpolação espacial

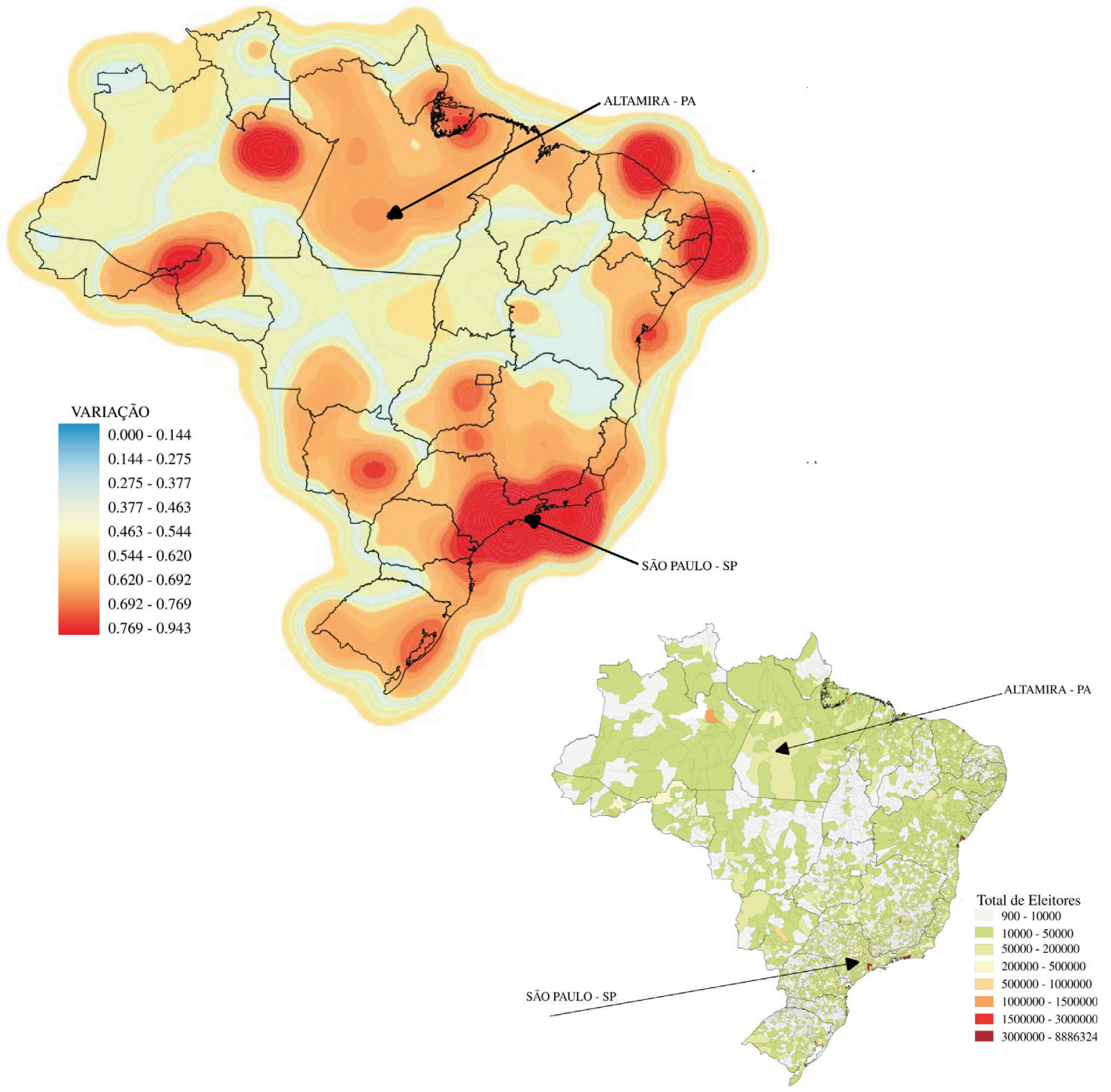

Fonte: Elaborado pelos autores com base nos dados do TSE. 
brasis", um no sudeste e sul, e outro no nordeste e norte, separados por um corredor relativamente "vazio" que se estende desde o sudoeste da Bahia, sul do Piauí, Tocantins, norte de Mato Grosso até o noroeste do Amazonas, além de outros núcleos menores e segmentados. Tal qual apontado para as modelagens anteriores, a Figura 8 também poderia representar as concentrações de dados de candidaturas, de financiamento, resultados eleitorais ou dados censitários e índices de aplicação e avaliação de políticas.

O uso da interpolação para fins de investigação e análise político-eleitoral demanda um esforço para a sua interpretação, além de uma considerável exigência de software e domínio técnico para sua operação. Todavia, uma investigação assim exigente não deveria prescindir de um investimento em equipes de pesquisa multidisciplinares capazes de análises e geração de resultados complexos, pois poucos outros recursos seriam capazes de deixar tão evidente a densidade de acontecimentos ou a resultante e o alcance de políticas públicas no país.

\section{Conclusões}

Este artigo evidenciou as limitações das representações espaciais com base no usual modelo coroplético ancorado nas poligonais da divisão político-administrativa para a representação de dados de caráter populacional e apresentou quatro modelagens de representação espacial (áreas iguais, 3D, anamorfose e interpolação) com potencial para minimizar os problemas evidenciados no padrão coroplético dominante no material científico analisado.

As comparações entre o mapa coroplético (Figura 1) e os ensaios produzidos demonstram o potencial das indicações para a visualização, interpretação e análise espacial dos dados eleitorais nas áreas de ciência política e geografia eleitoral. Pudemos verificar que os mapas coropléticos são insuficientes, mas verificamos também que nenhum dos modelos indicados pode ser considerado o mais adequado para expressar a dinâmica e a fluidez do fenômeno social, especialmente dos processos eleitorais. Para tal, faz-se necessária uma avaliação das condições de produção e destinação de cada uma dessas produções. Certamente, a conjugação de dois ou mais desses recursos pode produzir resultados bastante satisfatórios.

Convictos da necessidade de discutir o caráter político do mapeamento e as políticas de produção cartográfica, apresentamos uma resposta parcial para as necessidades de expressão espacial de nossas pesquisas com dados eleitorais, produzindo cartogramas que ampliam a capacidade de interpretação da dinâmica do fenômeno político. Demonstramos que a ciência política pode atender de forma mais robusta aos seus pesquisadores e ao público ao qual suas produções são destinadas. Todavia, tais avanços dependem da ampliação da oferta de conteúdos curriculares interdisciplinares voltados à espacialização do poder em estudos político-eleitorais e de políticas públicas tanto na graduação quanto em programas de especialização específicos. $\mathrm{O}$ artigo não esgota os desafios que se colocam em uma realidade que jamais está acabada, mas em constante transformação. Certamente a disponibilidade e popularização das tecnologias visuais trarão novas demandas e possibilidades a serem agregadas aos estudos político-eleitorais e de políticas públicas.

Ivan Jairo Junckes (ivanjj@ufpr.br) é Doutor em Sociologia Política pela UFSC e professor no Curso de Administração Pública da UFPR Litoral.

Wilson Silva Júnior (wilsonsilvajr13@gmail.com) é doutorando em Geografia na UEPG e consultor de projetos em geoprocessamento. 
Joseli Maria Silva (joseli.genero@gmail.com) é Doutora em Geografia pela UFRJ e professora do Programa de Pós-Graduação em Geografia da UEPG.

Edson Armando Silva (edameister@gmail.com) é Doutor em História pela UFF e professor no Departamento de História da UEPG.

\section{Referências}

Amorim Neto, O., Cortez, B.F. \& Pessoa, S. de A. (2011) Redesenhando o mapa eleitoral do Brasil: uma proposta de reforma política incremental. Opinião Pública, 17(1), pp. 45-75. DOI: 10.1590/S0104-62762011000100002

Augusto, D.C. (2017) Comportamento geográfico do voto: a identificação partidária em Portugal e no Brasil. Tese de Doutorado. Maringá: Universidade Estadual de Maringá.

Avritzer, L., Milani, C. \& Braga, M. do S. (2016) A ciência política no Brasil: 1960-2015. Rio de Janeiro: Editora FGV.

Barreto, M.C., Kosminsky, D. \& Esperança, C. (2018) Hexagonal hierarchical cartogram: Towards a thematic map of Brazil. InfoDesign-Revista Brasileira de Design da Informação, 15(1), pp. 45-62. DOI: 10.51358/id.v15i1.563

Barros, O.N.F. (2013) Análise cartográfica do confronto presidencial PSDB-PT no Paraná: período 1998-2010. Geosul, 28(56), pp. 131-146. DOI: $10.5007 / 2177-5230.2013 v 28 n 56 p 131$

Barros, O.N.F. \& Nagy, A. (2016) Eleições para o senado no Paraná: período 1994-2014. Confins. Revue Franco-Brésilienne de Géographie/Revista Franco-Brasilera de Geografia, 27. Disponível em http://journals.openedition.org/confins/10981. Acesso em 11 de ago. 2020. DOI: 10.4000/confins.10981

Bertin, J. (1986) A neográfica e o tratamento gráfico da informação. Curitiba: Ed. da UFPR.

Black, J. (2000) Maps and politics. Londres: Reaktion Books.

Bosque-González, I. del, Fernández Freire, C., Martín-Forero Morente, L. \& Pérez Asensio, E. (2015) Los sistemas de información geográfica y la investigación en ciencias humanas y sociales. Madrid: Confederación Española de Centros de Estudios Locales, Consejo Superior de Investigaciones Científicas.

Braga, M. do S. \& Zolnerkevic, A. (2020) Padrões de votação no tempo e no espaço: classificando as eleições presidenciais brasileiras. Opinião Pública, 26(1), pp. 1-33. Disponível em: https://periodicos.sbu.unicamp.br/ojs/index.php/op/article/view/8659514. Acesso em: 6 de dez. 2021.

Carvalho, D. \& Santos, G.F. dos. (2015) Ciclos políticos, socioeconomia e a geografia eleitoral do estado da Bahia nas eleições de 2006. Revista de Sociologia e Política, 23(54), pp. 109-135. DOI: 10.1590/1678-987315235407

Corrêa, D.S. (2015) Os custos eleitorais do Bolsa Família: reavaliando seu impacto sobre a eleição presidencial de 2006. Opinião Pública, 21(3), pp. 514-534. DOI: 10.1590/1807-01912015213514

Crampton, J.W. (2009) Cartography: performative, participatory, political. Progress in Human Geography, 33(6), pp. 840-848. DOI: $10.1177 / 0309132508105000$

Câmara, G., Davis, C. \& Monteiro, A.M.V. (2001) Introdução à ciência da geoinformação. São José dos Campos: Instituto Nacional de Pesquisas Espaciais.

Dutenkefer, E. (2010) Anamorfose como mapa: história, aplicativos e aplicações. In: $3^{\circ}$ Simpósio Iberoamericano de História da Cartografia. São Paulo.

Dutenkefer, E. (2018) A cidade e o mapa: representações cartográficas da urbanidade de São Paulo. Tese de Doutorado. São Paulo: Universidade de São Paulo.

Faganello, M.A. \& Fernandes, J.L.M. (2018) Migração partidária nos municípios brasileiros (2000-2016). Revista de Sociologia e Política, 26(66), pp. 101-124. DOI: 10.1590/1678-987318266605

Field, K. \& Dorling, D. (2016) UK election cartography. International Journal of Cartography, 2(2), pp. $202-232$. DOI: $10.1080 / 23729333.2016 .1238744$

Forest, B. (2018) Electoral geography: From mapping votes to representing power. Geography Compass, 12(1). DOI: $10.1111 / \mathrm{gec} 3.12352$

Gonçalves, R.D. (2016) Onde agrego os votos?: contribuições à geografia eleitoral aplicada a problemas político-eleitorais brasileiros. Dissertação de Mestrado. Curitiba: Universidade Federal do Paraná.

Gusein-Zade, S.M. \& Tikunov, V.S. (2017) Anamorphoses as a method of visualization. In: M. Lapaine \& E.L. Usery. Choosing a map projection. Cham (Switzerland): Springer International Publishing AG, pp. 161-176.

Harris, R., Charlton, M., Brunsdon, C. \& Manley, D. (2017) Balancing visibility and distortion: Remapping the results of the 2015 UK General Election. Environment and Planning A, 49(9), pp. 1.945-1.947. DOI: 10.1177/0308518X17708439

Hengl, T. (2009) A practical guide to geostatistical mapping. Luxembourg: Office for Official Publications of the European Communities.

Herb, G.H., Häkli, J., Corson, M.W., Mellow, N., Cobarrubias, S. \& Casas-Cortes, M. (2009) Intervention: Mapping is critical! Political Geography, 28(6), pp. 332-342. DOI: 10.1016/j.polgeo.2009.09.005

Hernández, V.H. \& De León, L. de H. (2020) Geografía de la participación electoral y diferenciación socioespacial en Ciudad Juárez, Chihuahua (México). Geopolítica (s), 11(1), pp. 145-172. DOI: 10.5209/geop.63962

Hewes, F.W. \& Gannett, H. (1883) Scribner's statistical atlas of the United States. New York: C. Scribner's sons.

Jacob, C.R., Hees, D.R., Waniez, P. \& Brustlein, V. (2009) A eleição presidencial de 2006 no Brasil: continuidade política e mudança na geografia eleitoral. Revista Alceu, 10(9), pp. 232-261. 
Jacob, C.R., César, R.H., Dora, W. \& Philippe y Brustlein, V. (2011) A eleição presidencial de 2010 no Brasil: continuidade política e estabilidade na geografia eleitoral. Rev Comun Cult Polít, 12, pp. 189-229.

Johnston, R., Pattie, C. \& Manley, D. (2017) Britain's changed electoral map in and beyond 2015: the importance of geography. The Geographical Journal, 183(1), pp. 58-70. DOI: 10.1111/geoj.12171

Johnston, R., Rossiter, D., Manley, D., Pattie, C., Hartman, T. \& Jones, K. (2018) Coming full circle: the 2017 UK general election and the changing electoral map. The Geographical Journal, 184(1), pp. 100-108. DOI: 10.1111/geoj.12240

Jones, A. \& Clark, J. (2020) Political geography and political science: common territory? Geopolitics, 25(2), pp. $472-478$. DOI: $10.1080 / 14650045.2019 .1643161$

Kerski, J.J. (2016) Critical thinking about elections maps and data. The Geography Teacher, 13(3), pp. 145-150. DOI: $10.1080 / 19338341.2016 .1196597$

Li, Z. \& Aryana, S. (2018) Diffusion-based cartogram on spheres. Cartography and Geographic Information Science, 45(5), pp. 464-475. DOI: 10.1080/15230406.2017.1408033

Magalhães, A.M., Silva, M.E.A. da \& Dias, F. de M. (2015) Eleição de Dilma ou segunda reeleição de Lula? Uma análise espacial do pleito de 2010. Opinião Pública, 21(3), pp. 535-573. DOI: 10.1590/1807-01912015213535

Markowska, A. (2019) Cartograms-classification and terminology. Polish Cartographical Review, 51(2), pp. 51-65. DOI: $10.2478 /$ pcr-2019-0005

Marzagão, T. (2013) A dimensão geográfica das eleições brasileiras. Opinião Pública, 19(2), pp. $270-290$. DOI: $10.1590 / \mathrm{S} 0104-62762013000200002$

Meireles, F. \& Rubim Andrade, L.V. (2017) Magnitude eleitoral e representação de mulheres nos municípios brasileiros. Revista de Sociologia e Política, 25(63), pp. 79-101. DOI: 10.1590/1678-987317256304

Monmonier, M. (2018) How to lie with maps. Chicago: University of Chicago Press.

Nafalski, G.P.N. (2020) Desenvolvimento da estrutura partidária local no contexto metropolitano: o PT na cidade de São Paulo. Tese de Doutorado. Campinas: Universidade Estadual de Campinas.

Nicolau, J.M. \& Terron, S.L. (2012) Uma cidade partida? As eleições para prefeito do Rio de Janeiro em 2008. In: $8^{\circ}$ Encontro da $A B C P$. Gramado.

Nicolau, J. \& Oliveira, L. (2017) Political science in Brazil: An analysis of academic articles (1966-2015). Sociologia \& Antropologia, 7(2), pp. 371-393. DOI: 10.1590/2238-38752017v723

Nusrat, S. \& Kobourov, S. (2016) The state of the art in cartograms. Computer Graphics Forum, 35(3), pp. 619-642. DOI: $10.1111 /$ cgf.12932

Nusrat, S. (2017) Cartogram visualization: methods, applications, and effectiveness. Tese de Doutorado. Tucson: University of Arizona.

Ondrejka, P. (2016) Mapping election results in proportional electoral systems. Journal of Maps, 12(sup1), pp. 591-596. DOI: $10.1080 / 17445647.2016 .1239558$

Ourednik, A. (2017) The third dimension of political mapping: exploiting map interactivity for a better understanding of election and referendum results. Cartography and Geographic Information Science, 44(4), pp. $284-295$. DOI: 10.1080/15230406.2017.1295820

Pereira, B.M. (2014) Geografia eleitoral: análise espacial dos votos dos deputados estaduais de Goiás nas eleições de 2006 e 2010. Dissertação de Mestrado. Goiânia: Universidade Federal de Goiás.

Power, T.J. \& Rodrigues-Silveira, R. (2019) Mapping ideological preferences in Brazilian elections 1994-2018: a municipal-level study. Brazilian Political Science Review, 13(1), pp. 1-27. DOI: 10.1590/1981-3821201900010001

Rodrigues-Silveira, R. (2013) Território, escala e voto nas eleições municipais no Brasil. Cadernos Adenauer, 14(2), pp. 167-192.

Samagaio, A.C.M.T. de C. (2015) Geografia eleitoral: análise espacial de vinte anos de resultados eleitorais. Tese de Doutorado. Lisboa: Universidade Nova de Lisboa.

Terron, S.L. (2009) A composição de territórios eleitorais no Brasil: uma análise das votações de Lula (1989-2006). Tese de Doutorado. Rio de Janeiro: Instituto Universitário de Pesquisas do Rio de Janeiro.

Terron, S.L. (2012) Geografia eleitoral em foco. Em Debate, 4(2), pp. 8-18.

Trindade, H. (2016) A ciência política na Universidade Federal do Rio Grande do Sul (UFRGS): etapa fundacional e de inserção nacional (1968-1980). In: L. Avritzer, C. Milani \& M. do S. Braga (orgs) A ciência política no Brasil: 1960-2015. Rio de Janeiro: Editora FGV, pp. 93-122.

\section{Outras fontes}

Kaggle (2020) [datarepository] BR_eleitoral_municipal. Disponível em: $<$ https://www.kaggle.com/datarepository/br-eleitoral-municipal>. Acesso em: 07 de dez. 2021.

GIS-Browser-memoriasdigitais.uepg (2021) CARTOGRAFIA_ELEITORAL. Disponível em: <http://memoriasdigitais.uepg.br/maps/CARTOGRAFIA_ELEITORAL>. Acesso em: 07 de dez. 2021.

TSE (2021) Repositório de Dados Eleitorais. Disponível em: <http://www.tse.jus.br/eleicoes/estatisticas/repositorio-de-dados-eleitorais-1/repositorio-de-dados-eleitorais>. Acesso em: 07 de dez. 2021. 


\section{Spatial representation of electoral data in Brazil: critique and possibilities}

Keywords: political science; election; spatial representation; map; cartogram.

ABSTRACT Introduction: Coropleth maps offer a poor representation of socioeconomic and political phenomena. Anchored to political-administrative polygons, these colorful state and city maps are mainly destined to the representation of territorial size. Thus, small areas with high population density or high number of voters almost disappear in the map. This paper discusses the use of these maps in political science and presents alternatives aiming to broaden the resources for spatial representation of political-electoral phenomena in Brazil. Material and Methods: We surveyed the academic production portraying the issue approached and carried out cartographic projections based on data provided by the Superior Electoral Court related to the number of voters apt to vote in the 2016 elections. The programs used in the modeling were: JamoviR for statistical analyses, Quantum Gis for operations based on tables and theme expression, and Saga Gis 3D and Grass for topological correction. Results: We demonstrated some limitations of the coropleth maps and indicated four cartographic models: equal-area, 3D, anamorphosis and interpolation. Discussion: The models indicated are methodological alternatives and contribute to broaden the research conditions in the electoral geography and political science areas.

This is an Open Access article distributed under the terms of the Creative Commons Attribution Non-Commercial License which permits unrestricted non-commercial use, distribution, and reproduction in any medium provided the original work is properly cited. 